\title{
Processo de Formação do Plano Estratégico: Um Estudo no Ministério do Planejamento, Orçamento e Gestão
}

\section{The Process of Formation of The Strategic Plan: A Study In The Ministry of Planning, Budget and Management}

\author{
Antônio Rocha Firmo Júnior ${ }^{1}$, Ricardo Ribeiro Rocha Marques ${ }^{2}$ \\ ${ }^{1}$ Universidade Estadual da Paraíba, UEPB, Brasil \\ ${ }^{2}$ Universidade Federal da Paraíba, UFPB, Brasil \\ Correspondência: Antônio Rocha Firmo Júnior. Endereço: Rua Baraúnas, 351, Universitário, Campina Grande, \\ PB CEP 58429500. Tel.: 5583 3315-3300.E-mail: juninho_22@live.com
}

Recebido: 02 de novembro de 2016 Aceito: 06 de julho de 2017 Publicado: 31 de outubro de 2017

DOI: http://dx.doi.org/10.21714/1679-18272016v14n2.p401-412

\begin{abstract}
Resumo
O planejamento ajuda a garantir que a organização permanece relevante e sensível às necessidades de sua comunidade, e contribui para estabilidade e crescimento organizacional. O objetivo deste estudo foi de analisar como ocorreu o processo de formação do plano estratégico do Ministério do Planejamento, Orçamento e Gestão (MP) - entre 2012 e 2015. Para tal, foi empregada a abordagem qualitativa, tendo como método o estudo de caso único e o instrumento adotado para a coleta dos dados foi a análise documental. A análise dos dados dividiu-se em três etapas: a da apresentação das principais metas estabelecidas pelo MP, os resultados alcançados em cada ano e a correlação das estratégias ao modelo de Mintzberg e Waters (1985). O trabalho possibilitou constatar que os macro-objetivos tiveram como características a estratégia planejada e a guarda-chuva, diferentemente dos processos internos, que tiveram o desenvolvimento das estratégias com foco no processo e, por fim, as ações de sustentação voltadas para a estratégia planejada e ideológica. Também foi possível constatar que metas estabelecidas pelo MP não foram cumpridas de acordo com o que fora planejado para o referido período.
\end{abstract}

Palavras-chave: Formação de estratégias; Ministério do Planejamento, Orçamento e Gestão; Modelo de Mintzberg e Waters (1985).

\begin{abstract}
Planning helps to ensure that the organization will stay relevant and aware of the needs of its community, as well as contribute to the organizational stability and growing. This study aims to analyze how was the process of formation of the strategic plan by the Ministry of Planning, Budget and Management (MP) - between 2012 and 2015. To do so, it was used the qualitative approach and the single case study method. For the data collection, the instrument chosen was the document analysis. Data analysis was divided into three stages: presentation of the main goals set by the MP, results achieved in each year and correlation of strategies to the Mintzberg and Waters model (1985). It was possible to note that the macro objectives had, as characteristics the emergent and deliberated strategies, unlike the internal processes that had the development of focused strategies in the process and, finally, the actions support for the emergent and ideological strategy. It was also established that goals set by the MP were not performed according with what had been planned for that period.
\end{abstract}

Keywords: Strategy formation; Ministry of Planning, Budget and Management; Mintzberg and Waters model (1985).

Esta obra está licenciada sob uma Licença Creative Commons Attribution 3.0.

\section{Introdução}

Entre os anos de 1950 e 1970, as organizações começaram a adotar novos instrumentos de gestão, cujas principais ferramentas foram o planejamento e o orçamento para o longo prazo. No entanto, com o passar dos anos e os avanços tecnológicos, esses instrumentos se tornaram ineficientes e passaram a exigir das organizações novas formas de dinamizar sua atuação diante das atuais necessidades.

Nesse contexto, os gestores passaram a formular estratégias que levem em conta o curto, o médio e o longo prazo e que definam as ações que deverão ser tomadas para que a organização consiga atingir seus objetivos (MUNDSTOCK, 2008). 
A estratégia sempre esteve relacionada à iniciativa privada, que, por meio de planos eficientes, procura ser mais competitiva e ter uma margem de lucro maior. Porém, ainda que de maneira tímida, o setor público vem adotando estratégias para prestar serviços de boa qualidade, adaptando-se aos fatores internos e externos. Seu conceito está intimamente vinculado à velocidade com que as mudanças ocorrem e que interfere em sua formulação, determinando caminhos que a organização deverá percorrer para atingir seus objetivos e sua missão (OLIVEIRA, 2011).

No setor público brasileiro, a estratégia teve um processo lento de maturação e, até hoje, é um dos maiores dilemas enfrentados pelos gestores, o que torna os serviços públicos ineficientes e com alto custo para o Estado (FERREIRA et al., 2013). Entregar resultados que melhorem os serviços públicos como (Saúde, Segurança, Educação) requer uma visão de longo prazo, e compreender onde estamos (presente) e saber onde queremos chegar (futuro) é a base que determina o sucesso de todo o processo (LADEIRA, 2009).

A partir de tal contexto, o objetivo deste trabalho é de analisar como ocorreu o processo de formação do plano estratégico do Ministério do Planejamento, Orçamento e Gestão (MP) - entre os anos de 2012 e 2015, tendo como base o modelo de Mintzberg e Waters (1985). Para alcançar tal objetivo, procedeu-se a uma análise documental dos arquivos digitais do Planejamento Estratégico e os Relatórios Anuais de Avaliação do PPA 20122015, com os objetivos específicos de expor as principais metas estabelecidas para esse período; verificar como as estratégias foram planejadas e implementadas.

Do ponto de vista acadêmico, compreender o processo de elaboração do plano estratégico é sobremaneira importante, porquanto possibilita analisar profundamente o tema 'formulação de estratégias e seus paradoxos'. Nessa perspectiva, pretende-se preencher uma lacuna na área do conhecimento de estratégias, no setor público, que é escasso, segundo estudos de Ferreira et al. (2013). Para o MP, o estudo possibilita uma visão macro das metas elaboradas para os anos de 2012 a 2015 e que se compreenda bem mais a dinâmica de operacionalização e de correlação das metas estabelecidas com os resultados alcançados.

Este artigo foi dividido em cinco seções, na próxima apresentam-se os conceitos de estratégia, diagnóstico estratégico e o Modelo de Mintzberg e Waters; na seção subsequente, descrevem-se os procedimentos metodológicos que caracterizam a pesquisa. Os resultados encontrados a partir dos dados coletados e analisados são apresentados na quarta parte, em que se investigou como foi feita a elaboração do plano estratégico do MP entre os anos de 2012 e 2015. E por fim, apresentam-se as principais considerações finais a respeito do tema investigado, assim como as limitações do estudo e sugestões para pesquisas futuras.

\section{Estratégia}

Há indícios de que a estratégia tenha surgido na esfera militar nos escritos de Sun Tzu (A Arte da Guerra) por volta de 500 a.C., com cunho ofensivo e defensivo adotados pelos generais como planos de guerra contra um inimigo. Apesar disso, no mundo científico o tema estratégia organizacional é bastante recente, com fortes debates em meados do século XX. A estratégia passa a ser tratada como uma integração entre objetivos, políticas e ações governamentais voltadas a tornar o trabalho de uma organização mais eficiente (SCHNEIDER, 2013).

Não existe um conceito específico que define estratégia devido a sua dimensão e complexidade, porém Mintzberg e Quinn (2001) apontam como sendo um plano racional, não dogmático e capaz de adaptar-se as mudanças ambientais e é integrada com toda a estrutura organizacional, sendo coerente com as metas, as ações e as políticas da organização a curto, médio e longo prazo. Para a elaboração do plano estratégico bem-sucedido, deve-se: descrever os valores fundamentais e a missão da organização, compreender as prioridades atuais e futuras e preparar programas, políticas e ações para implementar a estratégia. Afim de garantir coerência entre os fatores Wright, Kroll e Parnell (2010) determinam que a estratégia a ser adotada deve considerar os pontos fortes e fracos da organização, como também as oportunidades e ameaças do ambiente a qual esteja inserida.

Em sentido amplo, Oliveira (2011, p. 5) define estratégia como:

[...] um caminho, ou maneira, ou ação estabelecida e adequada para alcançar os resultados da organização, representados por seus objetivos, desafios e metas. Em uma situação pode ser considerada como estratégia quando existe interligação entre os aspectos internos - controláveis - e externos - não controláveis - da organização. É a situação em que existe uma identificada, analisada e efetiva interligação entre os fatores externos - não controláveis - e interno - controláveis - que visa interagir com as oportunidades e as ameaças ambientais externas ou perante os pontos fortes e fracos internos da organização.

Nessa mesma vertente, Mintzberg (2004) argumenta a importância na escolha da estratégia, pois é o alicerce de qualquer organização e quando mal elaborada provoca a médio e longo prazo uma estrutura organizacional frágil e incapaz de reagir a fatores externos. O plano formulado tem que responder as necessidades da organização levando em conta as vantagens e desvantagens da mesma permitindo atuar de maneira proativa. Trata-se um 
conjunto de ações únicas, desenvolvidas para resolver problemas e atender as necessidades conjunturais e estruturais de uma organização. (ANSOFF; McDONNELL, 1993).

Então, a estratégia é formulada como um guia de normas que permite a organização realizar suas atividades de maneira eficiente a longo prazo como alternativa de tentar antecipar o futuro e também reagir as variáveis ambientais do presente. Na medida que direciona a organização e os agentes envolvidos para o mesmo objetivo, determinando quais ferramentas devem ser adotadas e como os gestores podem usá-las para obter os objetivos pretendidos pela organização (COSTA; ALMEIDA, 2005).

Para que o gestor tenha um plano eficiente de acordo com as necessidades da organização é necessário a elaboração de estratégias que levem em conta a estrutura organizacional e o ambiente. Sendo assim, a eficiência do plano estratégico da organização só será possível mediante diagnóstico prévio do ambiente que a organização esteja inserida, que será abordado na próxima seção.

\subsection{Diagnóstico Estratégico}

Para a elaboração de um plano estratégico é necessário ter como ponto inicial a compreensão e análise do ambiente. A análise deve levar em conta todas as variáveis envolvidas para identificar as oportunidades e ameaças reais possíveis de ocorrer, sendo adotada como ferramenta para compreender a situação global da organização. O diagnóstico prévio do ambiente é importante para dar a organização a capacidade de potencializar suas vantagens e assim ter êxito (AZEVEDO, 2005).

Segundo Castro, Santos e Fernandes (2007), o diagnóstico ambiental deve-se levar em conta os fatores internos e externos. A análise interna procura verificar os pontos fortes, fracos e neutros que compõem a estrutura funcional de uma organização. Já a analise externa leva em conta as variáveis macro ambientais tais como: político, econômico, legal, tecnológico e cultural, que estão além do controle da organização e que possíveis alterações por menor que sejam, podem representar grandes ameaças ou novas oportunidades.

$\mathrm{Na}$ elaboração de um plano estratégico é necessário um rigoroso entendimento da situação interna da organização. Para tanto, a capacidade de transferir informações entre os colaboradores é fundamental. O conhecimento adquirido internamente é o principal recurso de uma organização, pois ter colaboradores cientes da importância na formulação de um plano possibilita maior coordenação, competência e comprometimento em todo o processo (OLIVEIRA, 2011).

A avaliação interna inicia-se por meio do questionamento dos tipos de respostas que a organização precisa para lidar, entre outras, com as inovações tecnológicas, a regulamentação, a economia e as mudanças nos hábitos da sociedade no geral (CUNHA; MELO, 2003). O entendimento do processo interno deve levar em conta três etapas do diagnóstico ambiental, que são: identificação dos sintomas e dos problemas considerando as questões que estejam dentro da esfera da tomada de decisão, orientado o plano organizacional para o aproveitamento de suas forças e a neutralização de suas fraquezas; priorização dos problemas ou fraquezas por meio de uma solução viável de acordo com o grau de importância por área de atividade e, por fim, identificação de suas causas e efeitos a partir da indagação das principais causas que interfere negativamente a eficiência da organização (TAVARES, 2010).

Para Wright, Kroll e Parnell (2010), a busca por modelos eficientes incluem compreensão de três recursos para análise interna: os recursos humanos (conhecimento, habilidade e atitude - $\mathrm{CHA}$ ) que sem eles a estrutura física por mais moderna que seja não funciona; os recursos físicos referentes aos equipamentos, matéria-prima e tecnologia e, por fim, os recursos organizacionais que representam a própria operacionalização das atividades existentes dentro da organização, como por exemplo compra de materiais, estrutura de comando e valores compartilhados entre os colaboradores.

Segundo Porter (1991), a análise externa representa a ação inicial na formulação de um plano estratégico. Toda organização deve levar em conta os impactos que cada variável externa pode provocar e como agir para minimizar estes impactos. Sua análise deve ser feita horizontalmente, voltada para o propósito de existência da própria organização, ou seja, com foco na visão e missão da mesma. A análise externa possibilita aos gestores questionar a real eficiência de seus planos, propiciando a elaboração de um novo plano a partir do conhecimento e aprendizado ao longo do tempo.

Para obter a compreensão macro do ambiente, Tavares (2010) destaca as seguintes fatores externos considerados importantes para a elaboração do plano: a econômica responsável por lidar com a produtividade e recursos disponíveis de uma região; demográfica e social que são referentes ao comportamento da população, sua longevidade e força de trabalho; política econômica interna e externa que são importantes para compreender a dinâmica do país adotada por cada ciclo governamental; legal referente as leis e normais responsáveis por regular as relações entre organização/organização, organização/governo e organização/cliente; tecnológica e 
natureza que são responsáveis pela mudança do comportamento organizacional, com adoção de novas ferramentas mais eficientes e que reduzam o impacto ambiental.

Mendonça e Soares (2009) consideram que as oportunidades e ameaças serão diferentes de uma organização para outra, a depender do seu segmento de atuação. Por exemplo, o avanço no uso da internet como meio de comunicação pela sociedade moderna representa uma ameaça aos atuais modelos de comunicação (Rádio e Televisão) e para os sites e revistas virtuais representa a oportunidade de expandir seus negócios. Sendo assim, os fatores externos representam uma via de mão dupla na qual o sucesso ou fracasso dependerá da ação e/ou reação da organização.

\section{Formulação da Estratégia Deliberada e/ou Emergente}

A formulação da estratégia é o primeiro passo quando se vai elaborar um plano em que se determina o que é preciso fazer, como fazer e o melhor caminho a ser seguido para pôr em prática as ações que se encaixem nas necessidades presentes e futuras da organização. A formulação é o momento em que se determinam as etapas, os prazos e os meios que serão fundamentais para concentrar os esforços da organização na execução do plano elaborado pelos responsáveis (MINTZBERG, 2004).

A dificuldade de manter um plano estratégico até o final é consequência das variáveis incontroláveis que provocam pequenas e grandes alterações no decorrer do processo. Pode ser aplicado da maneira como foi pretendido ou emergir dentro de um processo de formulação já em andamento. Seu modo de elaborar varia de organização para organização, porquanto os fatores internos e externos impactam as organizações de maneiras diferentes (MINTZBERG; AHLSTRAND; LAMPEL, 2000).

A estratégia deliberada é a que é pré-estabelecida e que leva em conta o que poderá acontecer em um futuro próximo, tendo como referência as experiências que já ocorreram no passado. É estritamente rígida e fechada para mudanças, porquanto foi previamente estabelecida para um modelo prescritivo que levou em conta as variáveis e as necessidades da organização (MARIOTTO, 2003).

Sua análise racional deriva de um pensamento voltado para ações guiadas por intenções claras, detalhadas e de conhecimento geral de todos os agentes envolvidos. Um plano deliberado, que é formulado a partir dos dados disponíveis naquele momento, e sua estratégia é definida para atingir os objetivos almejados. Suas decisões formais enfatizam o trabalho em equipe, focada no respeito à hierarquia e a um processo controlado restrito a mudanças, com a característica de atuação forte da gestão do topo hierárquico, visando preservar a essência do que foi planejado (MINTZBERG; QUINN, 2001).

Pereira (2006) entende que o fator determinante, quando se vai avaliar a eficiência da estratégia deliberada, é o próprio cumprimento do que foi estabelecido, para garantir sucesso na obtenção dos objetivos, ou se inicia um novo processo, caso o anterior fracasse. Isso demanda tempo para a organização, porque esperar o fim de um processo correndo o risco de fracassar é deixar a estrutura organizacional vulnerável e sujeita ao agravamento dos problemas ao longo do tempo. E se o plano preestabelecido não atingir o objetivo esperado, a organização deve agir rápido, para evitar mais problemas, e estabelecer novos caminhos.

Não é possível afirmar, como entende Mintzberg (2004), que todas as estratégias são previamente determinadas e seguidas em um plano fixo (deliberadas). Isso se justifica porque as interferências de forças políticas, tecnológicas, legais ou econômicas por padrões de comportamento ainda não externados impedem sua exatidão quando se formula o plano estratégico, em que o papel do gestor é de saber analisar o contexto e atuar no momento oportuno.

Considerando que várias pressões ambientais não podem ser previstas principalmente em médio e em longo prazos, Mariotto (2003) determina a adoção de estratégias emergentes que ocorrem em um contexto não previsto. Suas ações são tomadas de maneira experimental, sujeitas a resultados atípicos e convergindo com o modelo informal, portanto, o oposto do modelo formal da estratégia deliberada.

A estratégia emergente é adotada depois ou no processo de execução das ações de um plano, promovida pelo aprendizado que ocorre ao longo do processo. A possibilidade de aprender, no âmbito do processo do planejamento, permite ao gestor a compreensão macro da situação atual e possibilita aplicar novas ideias que antes não foram cogitadas na elaboração do plano. Isso é possível, porque o processo da formulação de estratégia acontece de maneira contínua até a obtenção do objetivo determinado (MINTZBERG; QUINN, 2001).

Segundo Mariotto (2003), seguir uma estratégia à risca é fatal para qualquer organização, principalmente depois que o processo de globalização, que aproximou as organizações e interligou diversos mercados, foi intensificado. Os objetivos pretendidos só serão alcançados se for possível adaptar a estrutura organizacional às forças do ambiente externo. Emergir com novas ideias representa uma ação saudável e necessária para a longevidade e a eficiência organizacional, porque, se não se adotarem estratégias emergentes, o plano fracassará à proporção que 
os desafios forem se intensificando (MINTZBERG, 2010, apud OLIVEIRA et al, 2011).

A iniciativa inovadora é fruto de uma ação coletiva diante das atuais necessidades, o que exige das organizações ação proativa para superar os problemas e minimizar as incertezas. Mudar é necessário, pois a formulação deriva de um processo de inter-relação entre os fatores internos e externos que interferem nas estratégias da organização, e quando não considerados, impedem ou dificultam a obtenção dos objetivos estabelecidos (MINTZBERG, 2004).

\subsection{Modelo de Mintzberg e Waters (1985)}

De acordo com Mintzberg e Waters (1985), para efeito de estudos organizacionais relacionados a estratégia, é possível traçar um contínuo no qual existem dois tipos extremos de organização: as que só têm estratégias deliberadas e as que só têm estratégias emergentes. Essas duas formas puras são muito raras. Para uma estratégia ser estritamente deliberada, a organização deve ter intenções puras, com um nível concreto relativo de detalhes. Esse plano tem de ser levado a cabo exatamente como pretendido. Para uma estratégia ser estritamente emergente, deve ser coerente com a ação, ao longo do tempo, mas sem qualquer intenção. Mas os autores argumentam que, entre esses dois extremos, existem oito tipos diferentes de estratégias que são comuns nas organizações de hoje, a saber:

\begin{tabular}{|l|l|}
\hline Estratégias & \multicolumn{1}{|c|}{ Principais características } \\
\hline Planejada & $\begin{array}{l}\text { Envolve intenções claras voltadas para o controle formal com objetivo de } \\
\text { transformar as intenções em ação coletiva com o mínimo de distorção. }\end{array}$ \\
\hline Empreendedora & $\begin{array}{l}\text { Formulada a partir de uma visão pessoal. Comum em organizações jovens e que } \\
\text { ocupam nichos de mercado relativamente estáveis. }\end{array}$ \\
\hline Ideológica & $\begin{array}{l}\text { Os membros da organização compartilham as mesmas visões, adotadas } \\
\text { ideologicamente entre os agentes envolvidos. }\end{array}$ \\
\hline Guarda-Chuva & $\begin{array}{l}\text { Há diretrizes gerais para o comportamento, limites definidos, e outros atores da } \\
\text { organização podem manobrar dentro desses limites. }\end{array}$ \\
\hline Processo & $\begin{array}{l}\text { A liderança influencia a estratégia indiretamente, ou seja, controla os processos da } \\
\text { estratégia e deixa as decisões de conteúdo para os demais atores. }\end{array}$ \\
\hline Não Conectada & $\begin{array}{l}\text { Uma parte da organização, uma subunidade ou, às vezes, até mesmo um indivíduo } \\
\text { é capaz de realizar o próprio padrão de ação. }\end{array}$ \\
\hline Consenso & $\begin{array}{l}\text { Atores convergem para o mesmo padrão ou tema para que se torne generalizada na } \\
\text { organização, sem necessidade de uma direção central ou controle. }\end{array}$ \\
\hline Imposta & $\begin{array}{l}\text { O ambiente força diretamente a organização a direcionar suas ações, } \\
\text { independentemente da vontade ou não dos líderes. }\end{array}$ \\
\hline
\end{tabular}

Quadro 1: Os oito tipos de estratégias mais comuns nas organizações de hoje

Fonte: Adaptado de Mintzberg e Waters (1985)

Na próxima seção descreve-se os procedimentos metodológicos, que serviram de suporte para a pesquisa e, consequentemente, para a elaboração do artigo.

\section{Aspectos Metodológicos}

Em virtude da temática investigada optou-se por uma abordagem qualitativa de modo a obter-se uma análise mais aprofundada do contexto escolhido. Este estudo ainda caracteriza-se por ser descritivo, tendo como método de investigação um estudo de caso.

A pesquisa foi realizada tendo como base as metas estabelecidas pelo MP para os anos de 2012 a 2015 e se limitou a compreender as 12 principais metas e sua aplicabilidade ao longo dos anos.

O processo de coleta de dados ocorreu por meio da análise documental dos arquivos públicos: Planejamento Estratégico 2012 - 2015 e os Relatórios Anuais de Avaliação do PPA referentes aos anos de 2012, 2013 e 2014, disponíveis em PDF (meio digital) pelo portal de notícias do Ministério do Planejamento, Orçamento e Gestão. Deve-se ressaltar que o ano de 2015 não foi analisado, visto que o relatório de avaliação desse ano estava indisponível no período de realização dessa pesquisa.

Os dados coletados foram analisados empregando-se a técnica da análise de conteúdo que auxilia o pesquisador a descrever e a compreender o material escrito (CAREGNATO; MUTTI, 2006). A análise do conteúdo ocorreu em três etapas: a primeira buscou expor como ocorreu a elaboração do plano estratégico do MP, e a segunda etapa identificou quais metas foram atingidas comparando-as com os resultados de cada ano. Por fim, a terceira 
etapa correlacionou as oito estratégias do modelo de Modelo de Mintzberg e Waters (1985) com as áreas de atuação (macro-objetivos que tratam dos impactos para a sociedade e os resultados institucionais por meio de um modelo governamental eficiente; processos internos ao qual ficam as metas destinadas a serem alcançadas aos órgãos centrais existentes no Ministério e ações de sustentação com o intuito de assistir a ministra de Estado na definição de diretrizes e coordenação das atividades das secretarias) do ministério.

Diante da exposição sobre os aspectos metodológicos da pesquisa destacam-se, a seguir, os resultados obtidos provenientes da análise dados resultantes da operacionalização desta pesquisa.

\section{Características e Principais Metas Estabelecidas Pelo MP}

Criado em 1962, no governo de João Goulart, o ministério detinha as atribuições de planejar e coordenar a política econômica brasileira. Ao longo dos anos, suas atribuições foram se modificando, com mais e menos importância, a depender do governo de cada período. De ministério, passou a atuar como Secretaria de Planejamento, Orçamento e Coordenação da Presidência da República - SEPLAN, subordinada ao ministério da Economia. Com a gestão de Fernando Henrique Cardoso, começaram as reformas administrativas para o modelo gerencial, a SEPLAN foi substituída pelo ministério do Planejamento, Orçamento e Gestão - MP - e recuperou seu status de Ministério até os dias atuais.

Atualmente, o MP é o órgão responsável pela definição das diretrizes gerais de ação do Estado brasileiro, que visam torná-lo mais eficiente. Como sua missão é de "planejar e coordenar as políticas de gestão da administração pública federal, para fortalecer as capacidades do Estado para promoção do desenvolvimento sustentável e do aprimoramento da entrega de resultados ao cidadão", compete ao MP os seguintes assuntos: participação na formulação do planejamento estratégico nacional; avaliação dos impactos socioeconômicos das políticas e dos programas do Governo Federal; gestão dos sistemas cartográficos e estatísticos nacionais; viabilização de novas fontes de recursos para os planos de governo; coordenação da gestão de parcerias públicoprivadas; formulação de diretrizes, coordenação e definição de critérios de governança corporativa das empresas estatais federais; política e diretrizes para modernização da administração pública, entre outros.

A elaboração do planejamento estratégico do MP iniciou em agosto de 2011, com o propósito de definir metas a serem alcançadas nos anos de 2012, 2013, 2014 e 2015. Para garantir que o plano esteja de acordo com a missão e a visão de futuro do ministério, foi definido um roteiro a ser seguido pelos indivíduos envolvidos em sua elaboração. Isso garante a solidez do plano, pois, segundo Travares (2010), definir suas metas de acordo com a visão da instituição representa a projeção do lugar que se pretende que ela ocupe no futuro e orienta quais ações se devem executar para que isso ocorra.

Para integrar todas as metas estabelecidas, foi elaborado o mapa estratégico, que busca sintetizar pontos considerados importantes e que, ao longo dos anos, serão implementados pelo órgão. Sua elaboração focou nos impactos para a sociedade, nos processos internos e nas ações de sustentação do próprio ministério. Atitudes como essa garantem a elaboração de um plano robusto, que identifica grandes questões estratégicas e considera as forças externas e internas que interferem na implementação do plano (MINTZBERG, 2010, apud OLIVEIRA et al, 2011).

No Quadro 02, apresentam-se as 12 metas listadas no documento Plano Estratégico 2012 - 2015 do MP e que serão comparadas, posteriormente, com os dados disponíveis nos relatórios anuais de avaliações de cada ano. Vale ressaltar que as metas apresentadas a seguir fazem parte do plano, mas existem outras metas que não serão analisadas neste trabalho porque não se enquadram na temática da pesquisa. Para a escolha das metas, foram levados em consideração três requisitos: as características do conteúdo das metas em relação a objetividade para prestação dos serviços públicos, o nível de fecundidade das metas no decorrer dos anos e coparticipação entre a União, os estados e os municípios, como também, a sociedade de modo geral para a efetividade das metas.

\begin{tabular}{|c|l|}
\hline Áreas de atuação & \multicolumn{1}{c|}{ Resultados esperados } \\
\hline \multirow{4}{*}{ Macro-objetivos } & - Melhor funcionamento do Estado com otimização dos Recursos; \\
& - Ampliação da oferta de serviços públicos de excelência; \\
& - Integração das ações de planejamento do Governo; \\
& - Desenvolvimento acelerado e sustentável de setores estruturantes do país; \\
\hline \multirow{3}{*}{ Processos internos } & - Coordenarace viabilizar a execução de grandes obras de infraestrutura; \\
& - Racionalizar o processo de alocação de recursos; \\
& - Ampliar a sustentabilidade nas compras e contratações; \\
& - Formular diretrizes, coordenar e definir critérios de governança corporativa das \\
& empresas estatais federais; \\
\hline
\end{tabular}




\begin{tabular}{|l|l|}
\hline \multirow{3}{*}{ Ações de sustentação } & - Adotar as melhores práticas de gestão e governança, eliminando gargalo; \\
& - Aprimorar a eficiência mediante revisão de custos e de alocação de recursos; \\
& - Desenvolver cultura institucional voltada à excelência. \\
\hline
\end{tabular}

Quadro 2: Principais metas definidas pelo MP para 2012-2015

Fonte: Ministério do Planejamento, Orçamento e Gestão 2011

A seguir, serão apresentados os resultados analisados e comparados com as metas expostas no Quadro 02 .

\subsection{Resultados analisados referentes ao ano de 2012}

Inicialmente, o que se destaca, neste ano, é o aumento da taxa de investimento. Em suas metas, o MP define a continuidade da expansão do investimento ao longo dos próximos anos, estimulado, principalmente, pelos eventos mundiais previstos, como forma de desenvolvimento sustentável e acelerado por meio do Programa de Aceleração do Crescimento (PAC). Em 2012, o investimento cresceu 4,4\%, impulsionado pelas Estatais Federais e pela parceria entre o público e o privado que, consequentemente, estimularam a produção e a geração de empregos diretos e indiretos.

O crescimento dos investimentos em 2012 garantiu que se realizasse o que foi estabelecido no Plano Estratégico elaborado pelo Ministério que, além de apontar a perspectiva de crescimento, frisou que o setor público atuaria como o principal responsável pelos investimentos diretos no país. Os resultados apresentados comprovam o que Mintzberg e Quinn (2001) já relatavam: que a adequação do planejamento estratégico representa o fator mais importante para a concretização das metas, pois oferece metodologias e técnicas estruturadas por meio das quais os envolvidos podem direcionar seus esforços a determinado ponto estratégico.

Seguindo, percebe-se que, novamente guiada pela necessidade de prestar serviços públicos de excelência ao cidadão, o MP busca aproximar o Estado da sociedade e compreender as necessidades atuais dos cidadãos. Com foco na democratização dos meios de comunicação, o Governo Federal intensificou, no ano de 2012, o Programa Nacional de Banda Larga - PNBL, que busca expandir o acesso à internet a regiões mais carentes do país. Saber onde atuar é fundamental, segundo Oliveira (2011), pois identificar as necessidades atuais possibilita desenvolver um plano focado nos principais anseios de determinada população. E quando falamos de setor público, é ainda mais importante porque o que está em jogo são as garantias fundamentais de cada cidadão.

Apesar da intensificação, o programa mostrou fragilidade em sua implementação. Foi estabelecido, inicialmente, um plano de adesão de 1 Mbps (megabyte por segundo) por R \$35, com limite de download de $500 \mathrm{MB}$, mas que, mesmo assim, na época, não atingia a velocidade mínima estabelecida que já era considerada baixa. Isso provocou a ineficiência do programa que, ao longo dos anos, deixou de ser prioridade do governo federal. Ladeira (2009) assevera que determinados políticas públicas, geralmente, não conseguem ser bem desenvolvidas devido à falta de conhecimento dos órgãos competentes sobre o problema em questão. Determinadas medidas são aplicadas somente com foco na quantidade e se deixa de lado a eficiência.

Com a meta de viabilizar grandes obras de infraestrutura social, o MP coordenou políticas de expansão do investimento impulsionadas pelo PAC juntamente com a integração de outros ministérios. Constatou-se que, no ano de 2012, destacaram-se os programas destinados à infraestrutura social, entre eles: Minha Casa Minha Vida, que visa ampliar o crédito para o financiamento da casa própria e gerar emprego direto na construção civil. Tendo como público-alvo a população das Regiões Norte e Nordeste entre negros e pessoas de baixa renda, o programa garante o acesso à moradia popular e fortalece o dinamismo da economia. Determinadas metas estabelecidas só serão realizadas caso haja o engajamento de outros órgãos do Estado envolvidos. Isso ocorre porque instituições estão integradas, e o trabalho em conjunto é necessário para a concretização dos objetivos firmados (CASTRO, SANTOS e FERNANDES, 2007).

\subsection{Resultados analisados referentes ao ano de 2013}

O estudo mostrou que, no ano de 2013, a meta definida para modernizar a gestão pública e fortalecer a governança foi desempenhada com base na gestão por resultados. Para o setor de petróleo e o de gás, foi criada a Pré-Sal Petróleo S.A. - PPSA (Decreto 8.063/2013), que fará a gestão dos contratos de partilha de produção e de comercialização de petróleo e gás natural, como também o processo de transparência ativa com prestações periódicas sobre os gastos dos projetos em execução.

É importante frisar que essas medidas foram desenvolvidas dentro do processo, em decorrência do aprendizado adquirido dois anos depois da elaboração do plano. As empresas estatais do país começaram a reformular sua gestão e a buscar um novo modelo de administração, coletando dados e comparando-os com resultados anteriores. O conhecimento adquirido no decorrer do processo serviu de instrumento para garantir a obtenção do determinado objetivo, porquanto permitiu analisar o andamento dos projetos firmados e corrigir possíveis falhas 
pelo aprimoramento proveniente da experiência adquirida (MINTZBERG; AHLSTRAND; LAMPEL, 2000).

Nesse ano, também se verificou melhoria na alocação dos recursos públicos. Com a adoção de novos procedimentos licitatórios, as compras públicas do Governo Federal passaram a assumir papel importante de dinamizador da economia. Sua atuação focou nas compras de alimentos da agricultura familiar e de produtos nacionais de micro e pequenas empresas, diversificando o uso dos recursos públicos de forma eficiente e otimizando os investimentos.

De acordo com o que fora planejado em 2011, a maximização dos recursos públicos em áreas estratégicas representaria avanços no desenvolvimento econômico, social e ambiental do país. O governo adotou um novo modelo licitatório que leva em conta o preço, os benefícios para a sociedade e os impactos econômicos e ambientais nas compras públicas. Mundstock (2008) já afirmava que, quando as estratégias são direcionadas a determinado ponto, a possibilidade de seu sucesso aumenta porque se define claramente o caminho que será percorrido, as ferramentas que serão usadas e quantos agentes serão envolvidos direta e indiretamente.

O MP também se preocupou com o equilíbrio das contas públicas e estabeleceu metas ambiciosas de racionalização dos recursos disponíveis, tendo como ponto de partida a Lei Orçamentária e os impactos das ações para a sociedade. Porém, em 2013, aconteceu o oposto. As despesas do governo federal aumentaram vertiginosamente, e isso comprometeu a solidez fiscal do país, tendo como destaques o aumento nas despesas de $0,3 \%$ PIB dos juros nominais e de $0,2 \%$ PIB nos benefícios previdenciários de acordo com os dados do ministério da fazenda. A atitude do governo federal em aumentar suas despesas comprometeu a atuação do próprio setor público. Segundo Tavares (2010), a administração pública brasileira ainda tem a dificuldade de equilibrar as contas públicas gastando além do que foi estabelecido e descumprindo a regra básica da gestão orçamentária: devem-se estimar as receitas e, depois, alocá-las em programas.

\subsection{Resultados analisados referentes ao ano de 2014}

$\mathrm{O}$ ano de 2014 configurou-se como um período de instabilidade e de incertezas. Metas importantes que foram estabelecidas no Plano Estratégico elaborado pelo MP não foram cumpridas. A primeira delas diz respeito à dívida líquida do setor público que aumentou $1,9 \%$ do PIB interrompendo um ciclo de quatro anos de queda. $\mathrm{O}$ aumento ocorreu em decorrência do agravamento da crise econômica e da redução da arrecadação do Estado, que precisou intervir para evitar o colapso das contas públicas.

Com a adoção de medidas de contingenciamento, o governo começou a cortar gastos e a priorizar os programas essenciais para o funcionamento do país, o que prejudicou a capacidade de implementar novas políticas públicas. Castro, Santos e Fernandes (2007) referem que, mesmo que o diagnóstico ambiental leve em conta a situação interna e os fatores externos, é provável que ações incontroláveis interfiram na execução do plano. Devem-se, no entanto, desenvolver alternativas para solucionar os problemas com a adoção de ações proativas de impacto imediato, com o propósito de evitar o agravamento da situação.

Nota-se, também, que o contingenciamento prejudicou os investimentos do governo e das empresas estatais que representaram, respectivamente, $1,11 \%$ PIB e $1,72 \%$ PIB no período de acordo com o relatório anual de avaliação. A diminuição da participação do Estado na atividade econômica interferiu no andamento das obras de infraestrutura importantes para o crescimento econômico e gerou um ambiente de incertezas para os investidores estrangeiros. Entre elas, a extensão da malha ferroviária que, em 2013, foi de 29,6 mil/km e, em 2014, foi reduzida para $27,5 \mathrm{mil} / \mathrm{km}$. A redução

A queda de $2,1 \mathrm{mil} / \mathrm{km}$ de expansão da malha ferroviária operante interrompeu o ciclo de expansão do setor, que vinha garantindo a redução de custos no deslocamento de mercadorias. A contingenciamento comprometeu o andamento da meta estabelecida pelo MP de viabilizar a execução de grandes obras de infraestrutura de transporte por meio do PCA 2, pois o governo reduziu a aplicação de recursos para as obras de infraestrutura. Os investimentos em obras de transporte contribuiria para haver uma eficiente rede de infraestrutura, reduzir os custos e melhorar a competitividade das empresas nacionais. Um dos pontos mais importantes na elaboração do plano consiste em informar e compreender a dinâmica da economia nacional e da internacional para se ter uma visão clara dos recursos disponíveis para cada período (TAVARES, 2010).

\subsection{Metas do MP e o modelo de Mintzberg e Waters (1985)}

As metas definidas no Plano Estratégico 2012 - 2015 representadas pelas três áreas de atuação (macro-objetivos, processos internos e ações de sustentação) foram comparadas com os oito diferentes tipos de estratégia (planejada - PLAN, empreendedora - EMP, ideológica - IDEO, guarda-chuva - G.CHU, processo - PROC, desconectada - DESC, consenso - CONS e imposta - IMP), definidas no Modelo de Mintzberg e Waters (1985). As metas foram classificadas em duas dimensões: as com forte orientação e as com fraca orientação para determinada estratégia e foram representadas, respectivamente, pelos sinais positivo $(+)$ e negativo $(-)$, conforme 
explicitado no Quadro 03.

\begin{tabular}{|c|c|c|c|c|c|c|c|c|}
\hline & \multicolumn{1}{|c|}{} \\
\hline Áreas de atuação & PLAN & EMP & IDEO & G.CHU & PROC & DESC & CONS & IMP \\
\hline Macro-objetivos & + & & & + & - & & & - \\
\hline Processos Interno & - & & & - & + & + & & \\
\hline Ações de Sustentação & + & & + & - & - & & & \\
\hline
\end{tabular}

Quadro 3: Metas estabelecidas e suas características

Fonte: Elaboração própria (2016)

Tendo em vista as informações analisadas, houve características que marcaram as áreas de atuação estabelecidas pelo MP. No que diz respeito aos macro-objetivos, suas metas foram elaboradas com intenções claras e que determinavam as ferramentas necessárias para a obtenção dos objetivos almejados. Pode-se notar que, além de coerente, o plano estratégico especificava como atingir as metas por meio do programa de aceleramento do crescimento - PAC.

Além de estratégias planejadas, o macro-objetivos tinha metas que não dependiam somente do ministério do Planejamento, Orçamento e Gestão para serem atingidas, uma vez que o novo pacto federativo define a redistribuição de papéis entre a União, os estados e os municípios, para simplificar a descentralização dos recursos. Segundo Mintzberg e Waters (1985), configura-se como um guarda-chuva, porque, nesse caso, o ministério define diretrizes gerais e deixa as decisões específicas para os estados e os municípios. Por fim, notam-se, também, as estratégias impostas e de processo mesmo que com fraca orientação. E por se tratar do setor público, suas ações sofrem interferências da opinião pública e de agentes políticos e econômicos que são impostas para a organização (COSTA; ALMEIDA, 2005).

Referente aos processos internos, as metas apresentam características de formação de estratégias denominada de processo, pois o MP definia os processos e deixava o conteúdo para outros níveis. Os órgãos específicos singulares (secretarias) e os do colegiado eram os responsáveis por executar os planos estabelecidos, como por exemplo, a Secretaria de Logística e Tecnologia da Informação - SLTI - que visa fortalecer as políticas públicas de uso estratégico do poder aquisitivo do Estado. Nesse caso, o MP controla o processo de formulação de estratégia e deixa para suas secretárias a responsabilidade referente ao conteúdo. Por causa da participação indireta do Ministério, as estratégias planejadas tiveram fraca orientação na área de atuação referente aos processos internos.

Concomitantemente aos processos internos, percebeu-se forte orientação para a estratégia não conectada. A principal delas é referente à meta de formular diretrizes de governança corporativa das empresas estatais federais que, segundo o próprio plano, "cabe ao Departamento de Coordenação e Governança das Empresas Estatais articular e induzir boas práticas de gestão junto às estatais ... com vistas a potencializar os investimentos em benefício da sociedade". De acordo com o modelo de Mintzberg e Waters (1985), as estratégias não conectadas se concretizam por serem desconectadas, e as unidades têm suas próprias estratégias de ação.

Por fim, temos as ações de sustentação, que representam a última área de atuação estabelecida no plano estratégico do MP. Nessa parte do plano, percebeu-se a característica do desenvolvimento de uma cultura institucional enraizada e voltada para a excelência e ao cidadão, por meio do compartilhamento de valores entre os colaboradores. Nesse caso, a forte orientação para a estratégia ideológica que, segundo Mintzberg e Waters (1985), ocorre quando os membros compartilham da mesma visão e de valores.

A seção seguinte deste artigo apresenta as conclusões do estudo, bem como as suas limitações e sugestões para investigações futuras.

\section{Considerações Finais}

Como já referido, o objetivo desta investigação foi de analisar como ocorreu o processo de formação do plano estratégico do Ministério do Planejamento, Orçamento e Gestão (MP) - entre 2012 e 2015.

Observou-se que, na administração pública, o processo evolutivo do planejamento é lento. Nele, procedimentos de estratégias deliberadas são substituídos por ações emergentes quando ocorrem alterações no contexto econômico e social. Tais alterações foram aplicadas de modo a conduzir as ações do governo federal para o cumprimento das metas estabelecidas em 2011 pelo Ministério do Planejamento, Orçamento e Gestão. Tal formação de estratégias, analisadas através de documentos, apresentou resultados diversos no tocante à forma de se obterem os resultados.

Em relação ao ano de 2012, foi possível elaborar projetos para a infraestrutura social do país, devido à parceria 
entre o público e o privado para a obtenção de mais investimentos nesse setor. $\mathrm{O}$ aumento na taxa de investimento possibilitou a expansão de programas sociais de inclusão para pessoas mais carentes. Já em 2013, o governo começou a aumentar suas despesas, e isso comprometeu a solidez fiscal do país. A maior atuação do Estado brasileiro na economia do país gerou sobrecarga no equilíbrio das contas públicas e prejudicou a obtenção das metas estabelecidas pelo MP para esse período. Por fim, o ano de 2014 foi marcado por instabilidade e incertezas que acarretaram no descumprimento das metas estabelecidas. Dessa vez, o problema foi o agravamento da crise econômica, que reduziu a arrecadação do Estado e forçou o governo a adotar medidas de contingenciamento que inviabilizaram a execução de grandes obras de infraestrutura de transporte para o país.

Outro ponto de interesse da pesquisa foi a correlação das metas com o modelo de Mintzberg e Waters (1985). No início, percebeu-se que os macro-objetivos firmados tiveram forte orientação para estratégias planejada e guarda-chuva, em que se detinha o foco nos objetivos. Para os processos internos, notou-se forte orientação para a estratégia de processo, cujo conteúdo ficava sob a responsabilidade de secretarias subordinadas ao MP, e a estratégia não conectada, de responsabilidade das estatais federais com a adoção de boas práticas de governança. Por fim, quanto às ações de sustentação, além de características da estratégia planejada, percebeu-se forte orientação para a estratégia ideológica, que estimulava o desenvolvimento de uma cultura institucional que visava à excelência na prestação dos serviços dentro do Ministério como também para a sociedade de modo geral.

Diante dos achados, é possível perceber que as abordagens de planeamento estratégico desenvolvidas no setor privado, se adotadas no setor público, ajudam as organizações a lidar com as recentes mudanças. Melhorar o desempenho, eficiência e efetividade no setor público exige não só um bom planejamento. Ele também precisa de um forte processo de implementação impulsionada por gestores que estão no topo hierárquico das decisões a serem tomadas e alinhando ao processo de planejamento corporativo do orçamento disponível do governo federal. No entanto, a abordagem de planejamento estratégico desenvolvida no setor privado deve ser aplicadas com cuidado e prudência para fins públicos.

Os órgãos do Estado necessitam atuar como agentes de transformação para que a sociedade saia ganhando, por meio de políticas públicas eficientes que melhorem os serviços públicos prestados pelo Estado e ao mesmo tempo tendo a responsabilidade fiscal na aplicação dos recursos disponíveis.

Assim, no presente estudo ressaltou-se a importância da formação de estratégia para a eficiência na prestação de serviços públicos. Mesmo com metas definidas previamente, dentro do processo e com o passar dos anos, é necessário que o plano seja flexível e mutável. As organizações públicas precisão ir se reorganizando e remodelando seus padrões de comportamento para que seja possível atingir as metas estabelecidas. Não é possível seguir exatamente o que foi planejado, como também não se pode apenas agir de maneira emergente para qualquer situação. É necessário, então, que as organizações públicas encontrem um meio termo e que seja capaz de manter suas características e agir no momento oportuno.

Uma das limitações deste estudo foi o fato de que só foi possível analisar documentos disponíveis apenas no site do próprio ministério. Seria importante analisar documentos de órgãos fiscalizadores para comparar com os dados disponíveis nos documentos do MP. Outro ponto a destacar foi que o relatório anual de avaliação ano-base 2015 não foi analisado, pois não estava disponível no período de coleta dos dados no portal de notícias do Ministério do Planejamento, Orçamento e Gestão.

Fica, ainda, como sugestão o aprofundamento em outros estudos que agreguem e desenvolvam o foco dessa análise. Assim, sugere-se investigar: analisar a elaboração de estratégia em outros ministérios importantes para prestação de serviços públicos; o processo de formação de estratégias em outras organizações públicas, como, por exemplo, os campi universitários e as empresas estatais e, por fim, novos estudos que visem analisar as relações estratégicas entre o setor público e o privado.

\section{Referências}

ANSOFF, H. IGOR; McDONNELL, E. J. Implantando a administração estratégica. 2. ed. São Paulo: Atlas, 1993.

AZEVEDO, C. G. D. Processo de formação das estratégias de organizações do setor de gastronomia sediadas no recife ao longo de suas trajetórias de desenvolvimento. Dissertação (Mestrado em Administração) -UFPE, Recife - 2005. Disponível em: <http://repositorio.ufpe.br/>. Acesso em: 25 de julho de 2016.

CAREgnato, R. C. A.; MUTTI, R. Pesquisa qualitativa: análise de discurso versus análise de conteúdo. Chácara das Pedras, Porto Alegre, RS: Scielo, 2006. Disponível em: <http://www.scielo.br/>. Acessado em: 20 
de maio de 2016.

CASTRO, J. B. B.; SANTOS, N. M. B. F.; FERNANDES, R. S. Gestão estratégica para redes de varejo farmacêutico: um modelo fundamentado no balanced scorecard. XXXI Encontro da Anpad. Rio de janeiro/RJ, 2007. Disponível em: <http://www.anpad.org.br>. Acesso em: 4 de agosto de 2016.

COSTA, B. K.; ALMEIDA, M. I. R. Estratégia: Direcionando negócios e organizações. São Paulo: Atlas, 2005.

CUNHA, C. R.; MELO, M. C. O. L. Planejamento e elaboração de cenários estratégicos: o caso da prefeitura municipal de vitória - es. Anpad, Minas Gerais - CEPEAD/UFMG, 2003. Disponível em: $<$ http://www.anpad.org.br>. Acesso em: 22 de jun. de 2016.

FERREIRA, V. R. S.; NAJBERG, E.; SOUSA, M. M.; BORGES, C. Jr. Pesquisa em estratégia no setor público no brasil: avaliação da produção científica no período 2007 - 2012. VI Encontro de Estudos em Estratégia - Anpad. Bento Gonçalves/RS, 2013. Disponível em: <http://www.anpad.org.br>. Acessado em: 1 de agosto de 2016.

LADEIRA, L. C. O recurso do conhecimento nas novas concepções de estratégia: a inclusão da participação e as implicações sobre o setor público. IV Encontro de Estudos em Estratégia - Anpad. Recife/PE, 2009. Disponível em: <http://www.anpad.org.br>. Acessado em: 4 de agosto de 2016.

MARIOTTO, F. L. Estratégia: mobilizando estratégias emergentes. Revista RAE, 2003.

MARTINS, G. A.; LINTZ, A. Guia para elaboração de monografias e trabalhos de conclusão de curso. $2^{\mathrm{a}}$ ed. São Paulo: Atlas, 2012.

MENDONÇA, A. P. G.; SOARES, T. D. L. A. M. Oportunidades e ameaças das alianças e redes na indústria de telecomunicações: foco nas empresas Embratel, Oi e Vivo. XXXI Encontro da Anpad. São Paulo, 2009. Disponível em: <http://www.anpad.org.br>. Acesso em: 30 de julho de 2016.

MINISTÉRIO DO PLANEJAMENTO. Planejamento Estratégico 2012 - 2015. Brasília - DF, 2011. Disponível em: <http://www.planejamento.gov.br>. Acessado em: 05 de setembro de 2016.

MINISTÉRIO DO PLANEJAMENTO. Relatório anual de avaliação do PPA 2012-2015 ano-base 2012. Brasília - DF. Disponível em: <http://www.planejamento.gov.br>. Acessado em: 05 de setembro de 2016.

MINISTÉRIO DO PLANEJAMENTO. Relatório anual de avaliação do PPA 2012-2015 ano-base 2013. Brasília - DF. Disponível em: <http://www.planejamento.gov.br>. Acessado em: 05 de setembro de 2016.

MINISTÉRIO DO PLANEJAMENTO. Relatório anual de avaliação do PPA 2012-2015 ano-base 2014. Brasília - DF. Disponível em: <http://www.planejamento.gov.br>. Acessado em: 05 de setembro de 2016.

MINTZBERG, H. Ascensão e queda do planejamento estratégico. Porto Alegre: Bookman, 2004.

MINTZBERG, H.; AHLSTRAND, B.; LAMPEL, J. Safári de estratégia: um roteiro pela selva do planejamento estratégico. Porto Alegre, Bookman, 2010.

MINTZBERG, H.; QUINN, J. B. O processo da estratégia. - 3. ed.- Porto Alegre: Bookman. 2001.

MINTZBERG, H.; WATERS, J. A. Of strategies, deliberate and emergente Strategic Management Journal, v. 6 , p. $257-272,1985$.

MUNDSTOCK, P. Relação entre o planejamento estratégico e desempenho superior. Dissertação de mestrado apresentada ao programa de pós-graduação da UFRGS. Porto Alegre/RS, 2008. Disponível em: $<$ http://www.lume.ufrgs.br/>. Acesso em: 17 de agosto de 2016.

OLIVEIRA, D. P. R. Administração estratégica na prática: a competitividade para administrar o futuro das empresas. - 7. ed. - São Paulo: Atlas, 2011.

OliveIRA, M. A.; SAUAIA, A. C. A.; MOTTA, G. S.; GARCIA, P. A. A. Combinando estratégias deliberadas e emergentes: um estudo com jogos de empresas. V encontro de estudo de estratégia - Anpad, 2011, Porto Alegre/RS. Disponível em: <http://www.anpad.org.br/>. Acessado em: 23 abril de 2016.

PEREIRA, Y. V. Processo de formação de estratégias da Accor Hotels do Brasil de 1974 a 2004.2006. Dissertação (Mestrado em Administração) - UFPE, Recife. Disponível em: < http://repositorio.ufpe.br/>. Acesso em: 13 de jul. de 2016.

PORTER, M. E. A estratégia competitiva. Rio de Janeiro: Campus, 1991.

SCHNEIDER, L. C. Pensamento estratégico organizacional: origens, evolução e principais influências. VI Encontro de Estudos em Estratégia - Anpad. Bento Gonçalves/RS, 2013. Disponível em: $<$ http://www.anpad.org.br>. Acessado em: 4 de agosto de 2016. 
Processo de Formação do Plano Estratégico: Um Estudo no Ministério do Planejamento, Orçamento e Gestão Revista Gestão.Org, v. 14, n. 2, 2016. p. 401-412 ISSN 1679-1827 http://www.revista.ufpe.br/gestaoorg

TAVARES, M. C. Gestão Estratégica. - 3ed. - São Paulo: Atlas, 2010.

WRIGHT, P.; KROLL, M. J.; PARNELL, J. Administração estratégica: conceitos. 4. ed., São Paulo: Atlas, 2010. 